\title{
Discussion on the Hot-Spot and Notch Stress Based Fatigue Assessment Methods Based on Test Results
}

\author{
B. J. Mecséri ${ }^{1}$ (D) B. Kövesdi ${ }^{1}$ (D
}

Received: 17 January 2019 / Accepted: 7 April 2020 / Published online: 21 April 2020

(c) The Author(s) 2020

\begin{abstract}
The focus of the current paper is the investigation of different local stress calculation methods for fatigue design. To evaluate the accuracy and applicability of the hot-spot and effective notch stress (ENS) fatigue assessment methods an experimental and numerical research program is carried out at the BME Department of Structural Engineering, in Hungary. Two types of structural details are tested using 32 test specimens, a cruciform and a gusset plate type joint. The test results and the accompanying numerical calculation results are statistically evaluated and compared. Analysing the results of the fatigue tests and numerical calculations, it is concluded, that both the hot-spot and the ENS method could be used for fatigue design of the cruciform joints according to the recommendation of the IIW (Hobbacher in Recommendations for fatigue design, Springer, Paris, 2004). However, the rules of the ENS method needs improvement, if used for the design of gusset plate type joint. According to the current results, the ENS method can be adjusted to make applicable for the gusset plate joints as well, recommendation for that is presented in the current paper.
\end{abstract}

Keywords Fatigue design $\cdot$ Hot-spot stress $\cdot$ Effective notch stress $\cdot$ Statistical analysis

\section{Introduction}

Nowadays, in the design praxis of steel bridges, the most commonly used fatigue assessment method is the nominal stress method. This approach is easy to use by bridge designers and there are numerous structural geometries, where this approach can be applied with high accuracy. However, this method can be used, if the structural detail has already been investigated before and the fatigue detail class has been verified by fatigue test results. Sometimes it is not easy to identify the correct standardized fatigue detail class for a unique geometry. The development of a new fatigue detail class requires a large number of fatigue tests, which is a time and cost consuming process. To avoid these disadvantages of the nominal stress method, local stress calculation methods were developed by researchers in the past, e.g. the hot-spot stress method and the effective notch stress method. The developments aimed at reducing the number of the further

\footnotetext{
B. J. Mecséri

mecseri.balazs@epito.bme.hu

1 Department of Structural Engineering, Budapest University of Technology and Economics, 3 Múegyetem rakpart, Budapest 1111, Hungary
}

necessary fatigue experiments, and simplifying the selection of the correct fatigue detail class to fatigue design.

However, the applicability of these fatigue assessment methods is currently still restricted, and is not verified for all kinds of structural details. In the current paper the accuracy and the applicability of the different local stress based fatigue assessment methods are investigated, and evaluated based on test results and numerical calculations. The experimental research program is carried out at the Budapest University of Technology and Economics, Department of Structural Engineering, in Hungary. The current paper focuses on the fatigue behavior of a cruciform joint and a gusset plate connection, which are frequently used structural details in bridges. A total of 32 fatigue tests are executed within this research program, the results of which are introduced in the current paper. Numerical models are also developed for each test specimen and the applicability of the hot-spot and the notch stress methods are evaluated. A numerical parametric study is conducted in order to investigate the effect of the numerical model input data on the computed stresses and on the applicability of the fatigue assessment method. Within the whole research program two different test specimens are studied, as-welded and post weld treated specimens. The 
current paper introduces the results of the as-welded type test specimens.

\section{Literature Review}

When investigating the fatigue lifetime of a welded structural detail, different stress calculation methods can be applied. The most common method is the global method, which is based on the nominal stresses (Bertini et al. 2018). For this method the $\mathrm{S}-\mathrm{N}$ diagrams of all investigated structural details must be determined. Therefore, numerous experiments are required to each different structural detail types so as to determine the actual $\mathrm{S}-\mathrm{N}$ curves. The test results related to other detail types cannot be used to calculate the FAT of the analysed structural detail. For numerous structural details fatigue test results were collected and statistically evaluated. More than 100 fatigue detail categories were previously determined by researchers, which can be found in standard EN 1993-1-9 (2005) or in the Recommendations of the International Institute of Welding (IIW) (Hobbacher 2004; Hobbacher 2009), etc. However, these fatigue detail classes cannot cover all the possible geometries of the design praxis, especially they are not applicable to new and innovative structural details. Therefore, fracture mechanics-based methods can be applied in order to determine the fatigue life of a detail with complex geometry (Zhang et al. 2018) or the generalization of the fatigue detail classes is required, which led to the development of the hot-spot and notch stress-based fatigue assessment methods. The idea of these methods is that peak stresses, or the stress concentration should be determined and the fatigue analysis can be performed using these values.

\subsection{Hot-Spot Stress Approach}

The hot-spot stress method (also called structural stress or geometric stress approach) is investigating the close environment of the fatigue critical point. The basic idea of this method is that the membrane and the bending stresses are included in the analyses of the critical fatigue point (hotspot), but the non-linear stress peak is neglected (Niemi and Marquis 2002). The effect of the notch is taken into account through test results, which were used to determine the S-N curve of the fatigue detail class. The advantage of the hot-spot stress method against the nominal stress method is that more complex geometries can be analysed. The FATs of this approach are not as strict as for the nominal stress approach. Therefore, geometries with complex shape can be easier classified to fatigue detail class (Hobbacher 2014). However, there is no recommended hot-spot fatigue detail class for every type of structural details. According to the IIW recommendation (Hobbacher 2014), the fatigue class of cruciform joints is FAT100, but this recommendation does not contain any guidance in choosing hot-spot fatigue class for gusset plate connections.

This method was firstly developed for analysing welded tubular joints in offshore structures (de Back 1987). It can be applied to details, where the fatigue crack initiates in the weld toe or at the end of the weld. When the crack propagates through the weld throat, this method is unsuitable for fatigue design. For the calculation of the hot-spot stresses the surface stress field should be computed in the closer region of the critical point, on which the hot-spot stresses are determined using extrapolation rules on special pre-defined stress evaluation points (Niemi et al. 2006). The extrapolation rule depends on the applied mesh size and the position of the critical point (located on the surface or at the plate edge). The extrapolation rules proposed by the IIW recommendations (Hobbacher 2014) are presented in Fig. 1. The necessary location of the extrapolation points were determined by Niemi and Fricke (Niemi et al. 2006). According to their investigations it can be seen, that there are two different types of hot-spots, the so-called "a" and "b" types, which depend on the location of the critical point. The research results of Niemi and Fricke showed that if the investigated critical point is on the surface of a plate, the extrapolation point locations should depend on the thickness of the plate. However, if a critical point is checked at the plate edge, this location can be given by constant distances. The extrapolation method can be linear or quadratic, for both ways the IIW Recommendations (Hobbacher 2014) give the positions of the extrapolation points, and the calculation methods to be used.

This method is a good alternative for fatigue design, if there are no fatigue detail classes for all the geometries to be checked.

\subsection{Effective Notch Stress Approach}

The effective notch stress method is a local stress approach, which has a large research background in the international literature (Olivier et al. 1989; Olivier et al. 1994; Niemi 2002; Radaj 1996; Lener et al. 2018). The basic idea of this method stems from Neuber's micro-support hypothesis (Olivier et al. 1989; Olivier et al. 1994). According to Neuber's concept (Fig. 2), a stress averaging is taken into account in the direction of crack propagation over a predefined length. The stress averaging is performed by the integration of the theoretical crack tip stresses over the micro-support length $\left(\rho^{*}\right)$. This length is a material parameter which can be determined by laboratory tests. The $\rho^{*}$ values were given by Neuber for different materials based on fatigue tests. It has to be noted, that the given parameter is yield strength-dependent, however all the current fatigue 


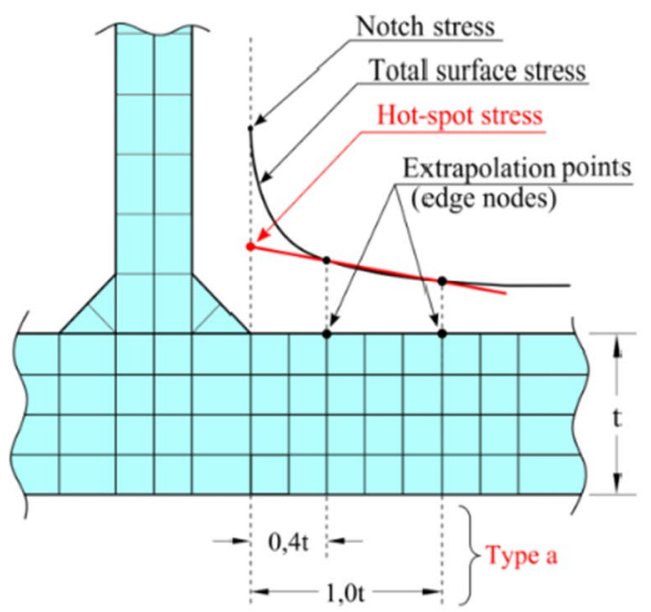

(Finely meshed model)
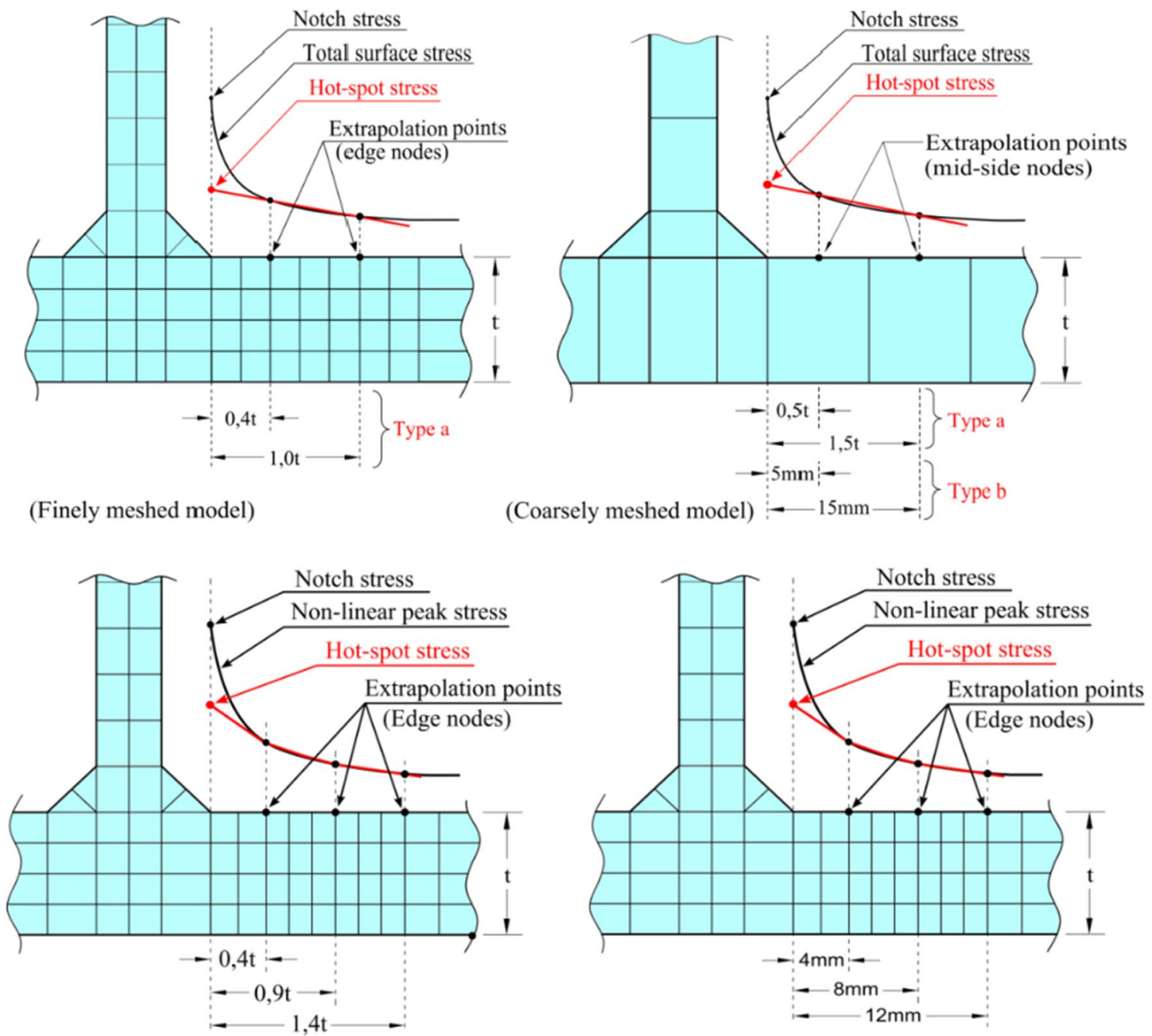

Fig. 1 Linear and non-linear extrapolation rules for hot-spot method (Al-Emrani and Aygül 2014)

(a) Actual notch with stress avaraging over $\rho^{\star}$

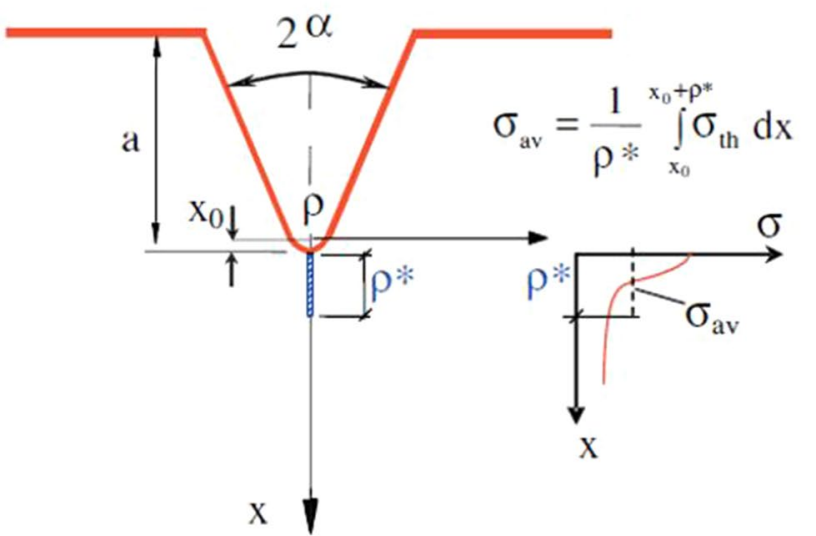

(b) Substitute notch with fictitous notch radius resulting in $\sigma_{\mathrm{av}}$

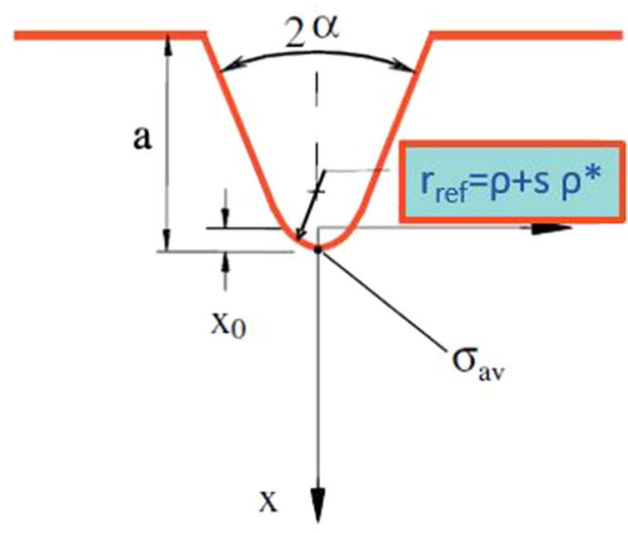

Fig. 2 Neuber's micro-support theory (Sonsino et al. 2012) 
assessment approaches are independent of the yield strength in the current standards.

Upon applying this theory, a reference radius is used for creating the finite element model of the analysed specimen. The value of the reference radius is calculated from the average stress at the notch tip. When using the correct radius at the critical fatigue points, the theoretically calculated average stress has to be determined by finite element analysis. The reference radius $\left(r_{\text {ref }}\right)$ can be calculated by the theoretical application of Neuber's formula based on Eqs. (1)-(2).

$r_{r e f}=\rho+s \cdot \rho^{*}$

$\sigma_{a v}=\frac{1}{\rho^{*}} \cdot \int_{x_{0}}^{x_{0}+\rho^{*}} \sigma_{t h} d x$

In the previous equation $s$ is the support factor, which depends on the loading mode. The parameter $\rho$ is the real notch radius, for which the theoretical stress field can be calculated.

According to Neuber's recommendation the reference radius should be set to $1 \mathrm{~mm}\left(s=2.5\right.$ and $\left.\rho^{*}=0.4 \mathrm{~mm}\right)$ for steel structures. This value comes from the worst case scenario, when the crack tip is sharp, and its real radius equals to zero.

This reference radius can be used only if the thickness of the investigated details is higher than $5 \mathrm{~mm}$. The applicable fatigue class for this method was determined based on statistical evaluation of previous test results. The fatigue classes of the global nominal stress method were converted according to the local stress approach. When the nominal stresses are applied on the FE models of different structural details, the local 1st principal stress was calculated at the fatigue critical point, and the new fatigue detail class for the local stress approach was determined based on the ratio of the nominal and the local stresses, which is the FAT225 (Sonsino et al. 2012) using a reference radius of $1 \mathrm{~mm}$ and the 1st principal stresses [Niemi (2002) are evaluated, Radaj (1996)]. This fatigue detail class was converted to the case of von Mises stress by Sonsino (2009). For the conversion the plain strain condition was assumed. The result of Sonsinos's calculations showed that the equivalent fatigue class for von Mises stresses is the $89 \%$ of the FAT using 1st principal stresses. Therefore, using von Mises stresses (which can be favourable in cases of multiaxial loading) the recommended fatigue detail class is the FAT 200 for steel structures. Recommendations for the applicable fatigue detail classes using $1 \mathrm{~mm}$ radius and for different stress calculation methods are given in Table 1 according to Sonsino (2009). However, the benefits of this method are evident, this method is not verified for all structural details. Therefore, numerous investigations are conducted recently on this topic as reported in
Table 1 Fatigue classes for different types of materials in the case of the effective notch method (Sonsino 2009)

\begin{tabular}{lll}
\hline$R_{\text {ref }}$ in $\mathrm{mm}$ & 1.00 & 1.00 \\
\hline Hypothesis & 1 st principal stresses & $\begin{array}{c}\text { Von Mises } \\
\text { stresses }\end{array}$ \\
Steel & 225 & 200 \\
Aluminium & 71 & 63 \\
Magnesium & 28 & 25 \\
\hline
\end{tabular}

(Sonsino et al. 2010; Fricke et al. 2017; Baumgartner 2017; Pedersen et al. 2010; Saad-Eldeen et al. 2010; Meneghetti and Lazzarin 2007; Taras and Unterweger 2013; Rother and Fricke 2016; Al Zamzami and Susmel 2018).

The Effective Notch Stress method contains the effect of local yielding. This approach is based on the statistical evaluation of fatigue test results, and the calculated notch stress is determined via the linear elastic calculation. Therefore, the effective notch stress is used only for considering the effect of different geometrical properties of the analysed structure. Plastic deformations could be also taken into account, if residual stresses due to welding would be determined and incorporated in the numerical model as well.

According to previous studies the ENS method has different results for different structural details. When test results of T-joints (Radaj et al. 2013; Sonsino et al. 2012; Radaj et al. 2006; Lee et al. 2005; Sonsino 2009) and non-loadcarrying cruciform joints (Sonsino et al. 2010; Fricke et al. 2017; Baumgartner 2017; Pedersen et al. 2010; Saad-Eldeen et al. 2010; Meneghetti and Lazzarin 2007; Muck 2005; Ohta et al. 2002; Huther et al. 2004; Lagerquist et al. 2007; Kuhlmann et al. 2006; Kudryavtsev 2007) are analysed, specimens show good agreement with the numerical results based on the ENS approach. However, the experimental results of numerous butt welded details (Sonsino et al. 2010; Saad-Eldeen et al. 2010; Meneghetti and Lazzarin 2007; Taras and Unterweger 2013; Rother and Fricke 2016; Al Zamzami and Susmel 2018; Haagensen 1997; Budano et al. 2007; Statnikov et al. 2002; Ohta et al. 2003; Lagerquist et al. 2007; Huther et al. 2004) analysed by the ENS method were consistently below the FAT225 S-N curve. Pedersen et al. (2010) explain this phenomenon by the defects of the butt welds, thus a modified S-N curve is recommended for this type of joints.

\section{Experimental Research Program}

To compare different stress calculation methods and to investigate them by fatigue test results, a fatigue experimental research program is carried out at the Budapest University of Technology and Economics to investigate the fatigue 


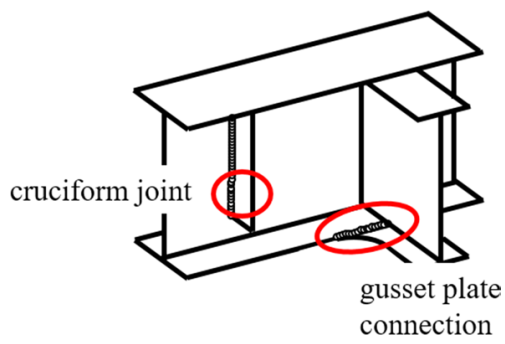

Fig. 3 Investigated structural details

behaviour of a cruciform and a gusset plate type connection. These two investigated structural details frequently appear in bridges in Europe (Fig. 3). The concept of research program was that two different detail types are investigated. One, which has been investigated in numerous previous studies, like non-load-carrying cruciform joints; and another, which is less examined in former papers, like gusset plate connections.

\subsection{Test Specimens and Set-Up}

A total of 32 fatigue tests have been conducted on cruciform (X-type) and flange gusset plate (II-type) type joint specimens. Two types of each geometry are investigated and presented in the current paper. The geometries and the dimensions of X-type specimens (X-10-norm and X-18-norm) are shown in Figs. 4 and 5. The geometries and parameters of II-type specimens (II-10-norm and II-18-norm) are shown in Figs. 6 and 7. Both types of specimens with a thickness of $10 \mathrm{~mm}$ (X-10-norm and II-10-norm) are manufactured from NSS (S235) and from HSS (S420) steel material to investigate the stress calculation methods for both steel grades. The $\mathrm{X}$-type specimens are fillet welded using weld throat thicknesses of $4 \mathrm{~mm}$ (X-10-norm) and $7 \mathrm{~mm}$ (X-18-norm) for
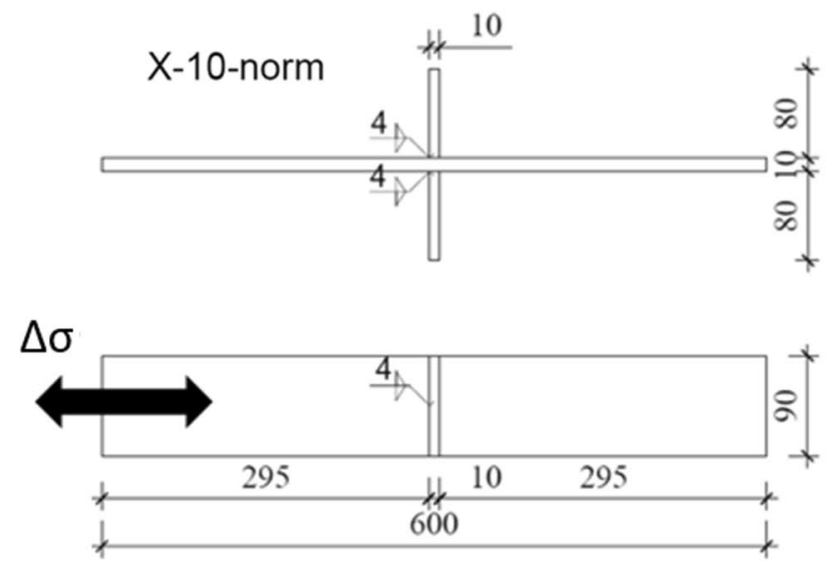

Fig. 4 Geometry of X-10 and X-18 type specimens

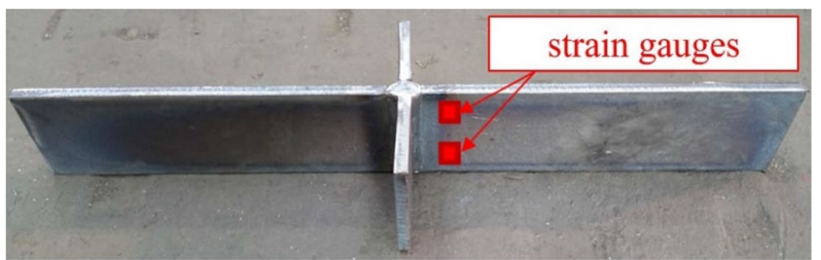

Fig. 5 Photo of an X-10 type specimen and the positions of strain gauges

the larger thickness. The joints of the II-type specimens are butt welded through the whole thickness of the steel plate.

All the specimens are loaded by a Mohr-Federhaff Losenhausen HUS40 pulsator. The applied loads are sinusoidal cyclic loads at constant amplitude. The minimum and the maximum forces are both tensions, to eliminate the effect of the crack closure. The minimum value of the cyclic load is $10 \mathrm{kN}$ for all test specimens. The investigated stress ranges of previous studies are usually higher than the usual stress range values acting in bridges. Therefore, this paper focuses on the lower stress range to examine the fatigue behaviour of steel bridges. During the fatigue tests the number of cycles is measured and recorded. Two strain gauges are placed on each specimen to monitor the stress range change, as shown in Figs. 5 and 7. At these points the strains are measured for $10 \mathrm{~s}$ with $0.2 \mathrm{~s}$ length interval and the strain-fatigue lifetime relationships are also evaluated.

\subsection{Fatigue Test Results}

The experimental results are the fatigue lifetime of the test specimens with different stress ranges applied in order that the relevant $\mathrm{S}-\mathrm{N}$ curves can be determine for all the analysed structural details. Important information is also taken from the crack pattern of the failed specimens. The location of
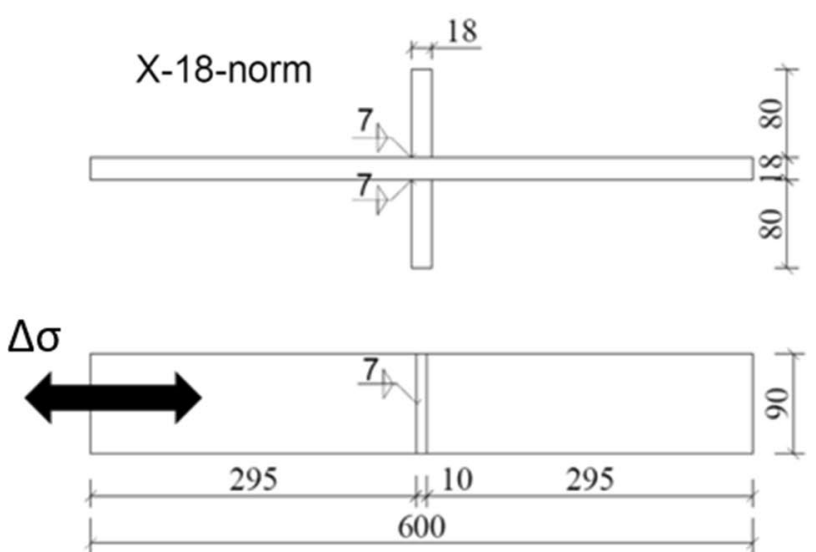

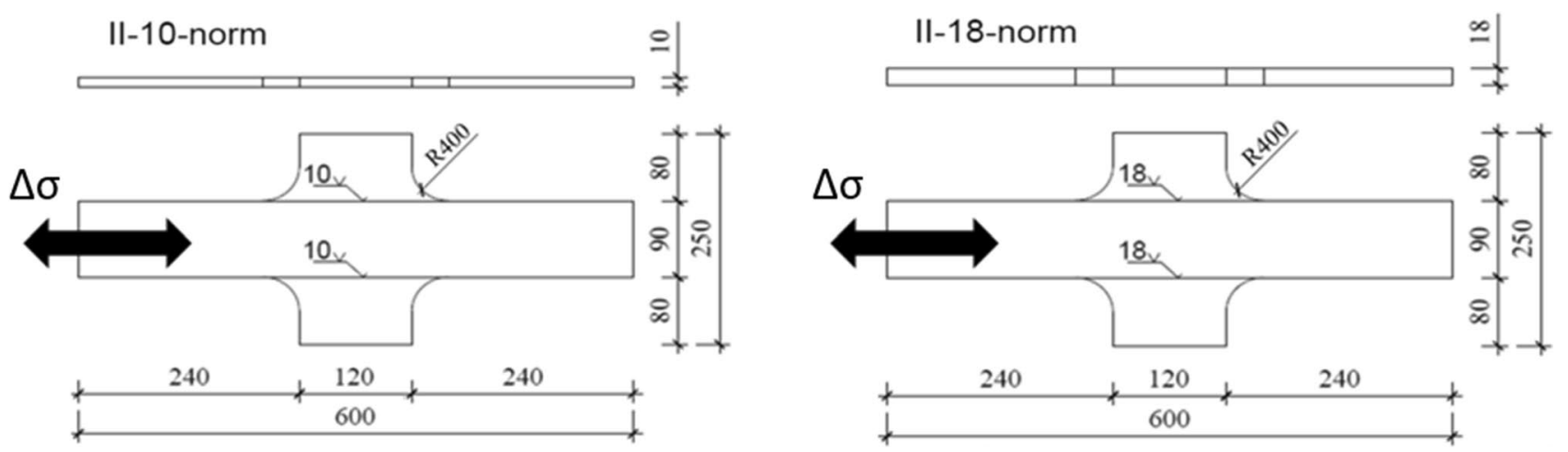

Fig. 6 Geometry of II-10 and II-18 type specimens

the crack initiation point and the crack propagation route are analysed and evaluated for each specimen. The measured strain data are also analysed by strain gauges, which show the stress range change close to the weld toes. The test results are summarized in Tables 2 and 3.

The tables contain the number of the test specimens, the applied material and geometrical properties, the applied load and stress ranges and the measured fatigue life cycles. The typical observed failure mode, the fatigue crack pattern and the measured stresses of both specimen types are presented in Fig. 8.

If we investigate the fracture surface of the X-type specimens it can be observed that the crack initiates in the base plate close to the weld toe, at the middle third of the plate width. The crack propagated through the thickness of the base plate, until it reached the opposite edge. After that the crack grew from the middle of the width to the edges of the base plate. The failure point can easily be recognized from the rough texture of the crack surface. The fracture surfaces of the II-type specimens are also studied. The analysis showed that the crack initiation point was always located at the end of the weld. The crack is a through-thickness crack, and it propagated perpendicularly to the longitudinal edge of the base plate. The failure point is on the opposite side

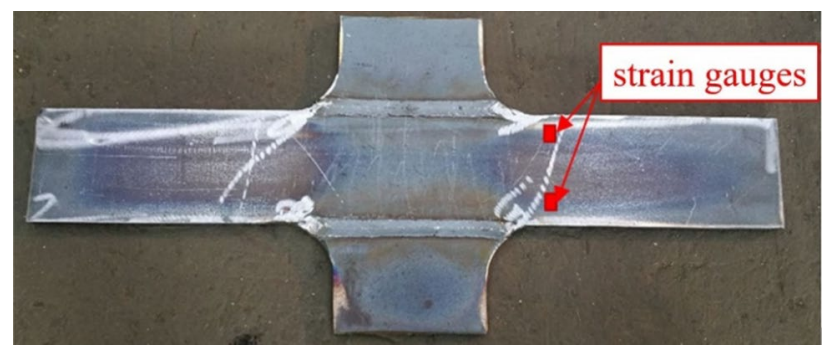

Fig. 7 Photo of an II-10 type specimen and the positions of strain gauges
Table 2 Parameters and results of the experiments on X-type specimens

\begin{tabular}{lllrrr}
\hline $\begin{array}{l}\text { No. of } \\
\text { speci- } \\
\text { men }\end{array}$ & Steel grade & $\mathrm{T}(\mathrm{mm})$ & $\Delta \mathrm{F}(\mathrm{kN})$ & $\Delta \sigma\left(\mathrm{N} / \mathrm{mm}^{2}\right)$ & $\mathrm{N}$ (cycles) \\
\hline 1 & $\mathrm{~S} 420$ & 10 & 90 & 100 & $6,327,900$ \\
2 & $\mathrm{~S} 235$ & 10 & 90 & 100 & $1,821,100$ \\
3 & $\mathrm{~S} 420$ & 10 & 135 & 150 & 538,000 \\
4 & $\mathrm{~S} 420$ & 10 & 110 & 122 & $1,313,200$ \\
13 & $\mathrm{~S} 235$ & 10 & 110 & 122 & 839,900 \\
15 & $\mathrm{~S} 235$ & 10 & 130 & 144 & 599,410 \\
16 & $\mathrm{~S} 235$ & 18 & 61 & 38 & $3,300,000$ \\
17 & $\mathrm{~S} 235$ & 18 & 220 & 136 & 286,900 \\
18 & $\mathrm{~S} 235$ & 18 & 160 & 99 & $1,239,900$ \\
30 & $\mathrm{~S} 420$ & 10 & 100 & 111 & 780,700 \\
32 & $\mathrm{~S} 235$ & 10 & 120 & 133 & 566,400 \\
33 & $\mathrm{~S} 420$ & 10 & 120 & 133 & 671,000 \\
34 & $\mathrm{~S} 235$ & 10 & 100 & 111 & 919,400 \\
35 & $\mathrm{~S} 420$ & 10 & 100 & 111 & $1,194,200$ \\
\hline
\end{tabular}

$\Delta F$ force range, $\Delta \sigma$ nominal stress range, $N$ number of cycles to failure

of the base plate, which can be seen from the rough part of the fracture surface.

During the whole test process the applied stress ranges are measured via using strain gauges placed on the specimens. The measured data was analysed, and the fatigue crack initiation was determined. The crack initiation point/time is defined by the cycle number where the difference of the current stress and the moving average is reached more than 5\% at measuring point. According to the recorded data it can be observed that the crack initiation is the dominant part of the fatigue lifetime of the X-type specimens, as shown in Fig. 9a. The fatigue lifetime of the II-type specimens can be divided into two approximately equal parts: (i) crack initiation and (ii) crack propagation phases, as shown in Fig. 9 b. 
Table 3 Parameters and results of the experiments on II-type specimens

\begin{tabular}{llllrrl}
\hline $\begin{array}{l}\text { No. of } \\
\text { specimen }\end{array}$ & Steel grade & Post weld treatment & $\mathrm{T}(\mathrm{mm})$ & $\Delta \mathrm{F}(\mathrm{kN})$ & $\Delta \sigma\left(\mathrm{N} / \mathrm{mm}^{2}\right)$ & $\mathrm{N}$ (cycles) \\
\hline 5 & $\mathrm{~S} 235$ & None & 10 & 90 & 100 & 210,100 \\
6 & $\mathrm{~S} 235$ & None & 10 & 60 & 67 & 270,700 \\
7 & $\mathrm{~S} 235$ & Disc grin. & 10 & 60 & 67 & $9,136,500$ \\
8 & $\mathrm{~S} 235$ & Disc grin. & 10 & 90 & 100 & 672,400 \\
9 & $\mathrm{~S} 420$ & Disc grin. & 10 & 90 & 100 & 646,600 \\
10 & $\mathrm{~S} 420$ & None & 10 & 70 & 78 & 548,900 \\
11 & $\mathrm{~S} 420$ & None & 10 & 90 & 100 & 275,200 \\
12 & $\mathrm{~S} 420$ & Disc grin. & 10 & 70 & 78 & 530,800 \\
14 & $\mathrm{~S} 420$ & Disc grin. & 10 & 60 & 67 & $\mathrm{n} . \mathrm{f}$. \\
19 & $\mathrm{~S} 235$ & None & 18 & 160 & 99 & 535,700 \\
20 & $\mathrm{~S} 235$ & None & 18 & 140 & 86 & 442,200 \\
21 & $\mathrm{~S} 235$ & None & 18 & 120 & 74 & 519,200 \\
22 & $\mathrm{~S} 235$ & Disc grin. & 18 & 160 & 99 & $15 \mathrm{E}+6$ \\
23 & $\mathrm{~S} 235$ & Disc grin. & 18 & 220 & 136 & $1,310,000$ \\
26 & $\mathrm{~S} 235$ & None & 10 & 60 & 67 & $1,121,400$ \\
27 & $\mathrm{~S} 235$ & None & 10 & 110 & 122 & 131,700 \\
28 & $\mathrm{~S} 235$ & None & 10 & 50 & 56 & $1,300,900$ \\
29 & $\mathrm{~S} 420$ & None & 10 & 50 & 56 & $1,019,600$ \\
\hline
\end{tabular}

$\Delta F$ force range, $\Delta \sigma$ nominal stress range, $N$ number of cycles to failure
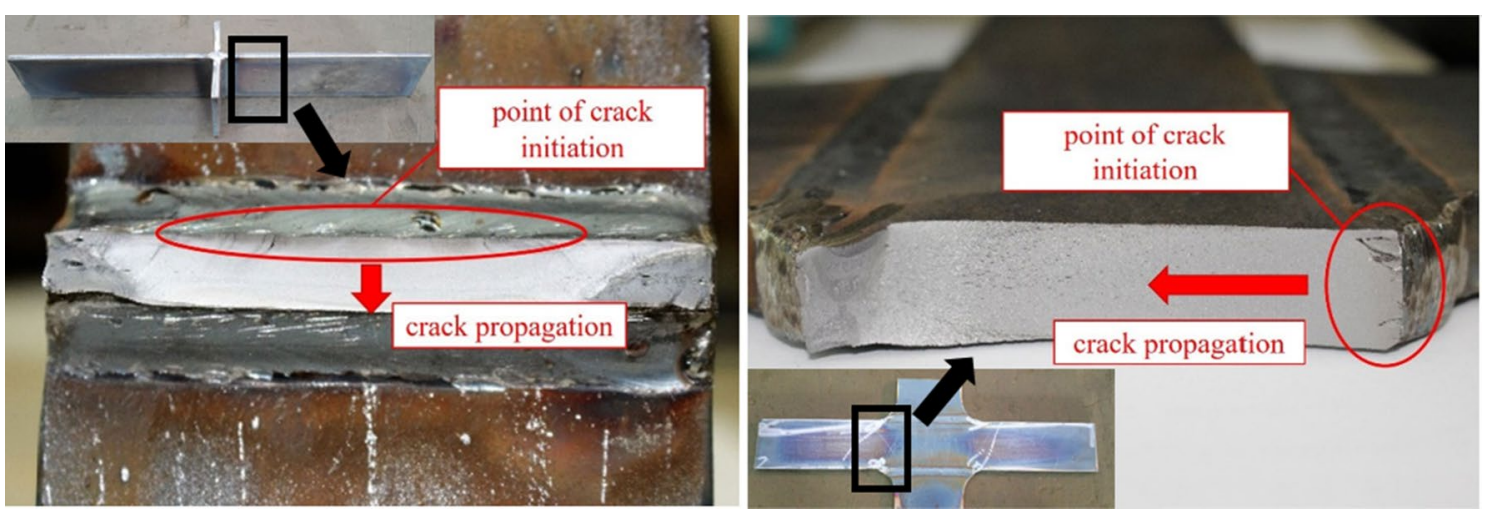

Fig. 8 Fracture surface of the X-type and II-type specimens

From the stress range-fatigue lifetime pairs the experimental S-N curves of the investigated details are determined and presented in Fig. 10 separately for both specimen types. The diagrams show the results of the specimens having different steel grades by different colours. Based on the test results it could be concluded that there are no large differences in the fatigue lifetime between the S235 and S420 specimens in the analysed parameter domain. However, upon evaluating the average values it seems that the S-N curve slopes are different for the different steel grades.

\section{Numerical Research Program}

The applicability and reliability of both the hot-spot and the effective notch stress methods are studied and presented in this Section. To determine the necessary stress ranges (hotspot or notch stresses) finite element models are developed to all the investigated specimen geometries according to the recommendation of the IIW (Hobbacher 2014).

\subsection{Numerical Models for Hot-Spot Stress Approach}

3D finite element models for both specimen types are developed in ANSYS 17.2 (Lener et al. 2018). The parameters of 


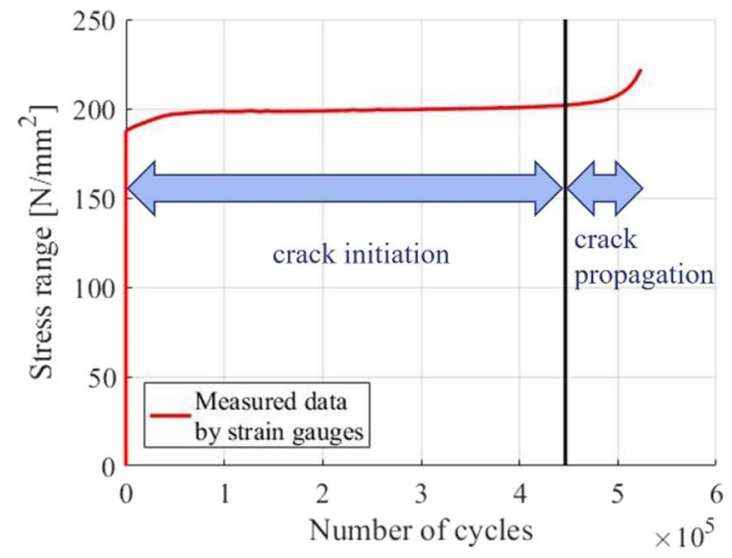

(a)

Fig. 9 Measured stress range of an $\mathbf{a}$ X-type and b II-type specimens

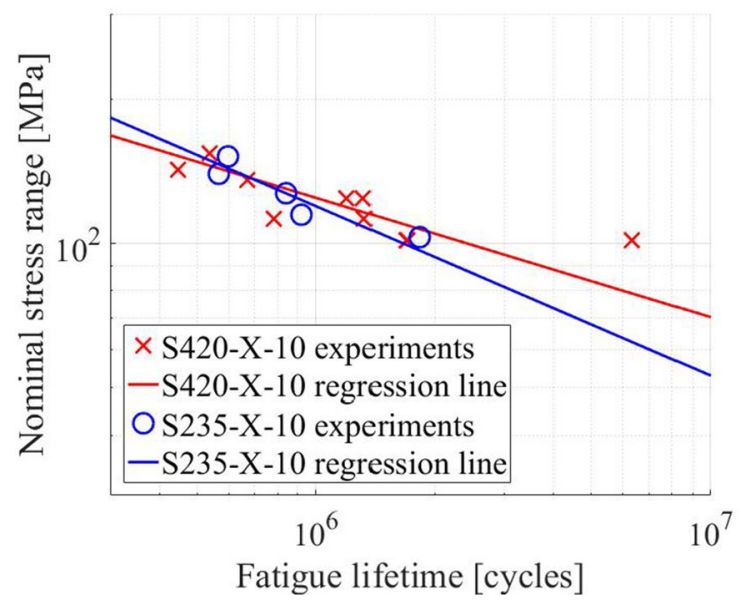

Fig. 10 Experimental S-N diagram of X-type and II-type specimens

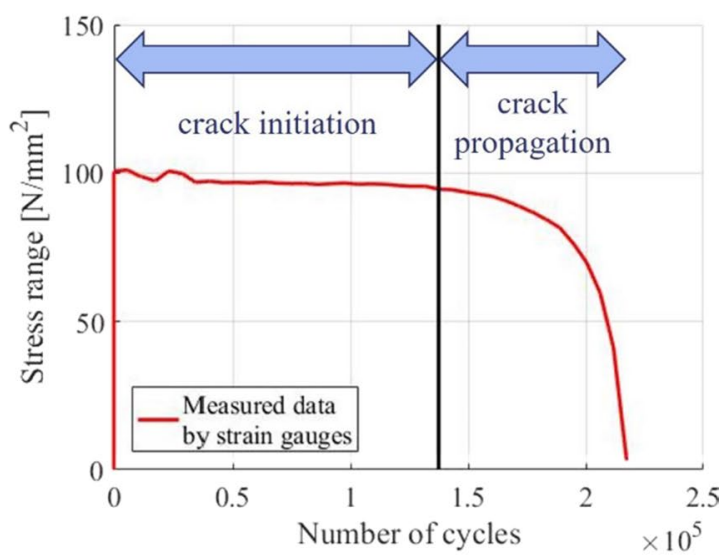

(b)

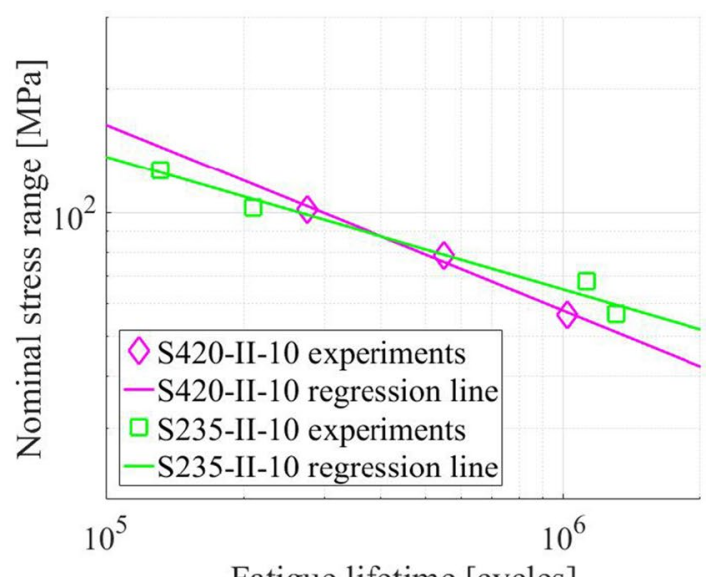

Fatigue lifetime [cycles]
Table 4 Parameters of hot-spot regression points for linear extrapolation

\begin{tabular}{|c|c|c|c|}
\hline \multicolumn{2}{|l|}{ Linear extrapolation (X-type) } & \multicolumn{2}{|l|}{ Linear extrapolation (II-type) } \\
\hline $\begin{array}{l}\text { Position of regression points } \\
\text { (mm from singularity point) }\end{array}$ & $\begin{array}{l}\text { Stress from numeric } \\
\text { model (MPa) }\end{array}$ & $\begin{array}{l}\text { Position of regression points } \\
\text { (mm from singularity point) }\end{array}$ & $\begin{array}{l}\text { Stress from } \\
\text { numeric model } \\
(\mathrm{Mpa})\end{array}$ \\
\hline $0.4 \mathrm{xt}$ & 108.67 & 5 & 138.05 \\
\hline $1.0 x t$ & 105.15 & 15 & 119.56 \\
\hline hot-spot & 111.03 & Hot-spot & 147.30 \\
\hline
\end{tabular}

the model act upon the recommendation of the IIW (Hobbacher 2014). The models are using twenty-node structural solid elements (SOLID186). The weld toes are modelled using sharp edges, and nodes are defined at the regression points for the further calculation. The position of these extra nodes are summed in Tables 4 and 5 together with an example for the computed normal stresses where $100 \mathrm{kN}$ tension force is applied on the specimen.

The symmetry of the specimens is used for reducing the number of the applied elements. In the case of the X-type and II-type specimens the one-eighth of the full specimen was modelled. The applied boundary conditions correspond to the symmetry conditions. The model is loaded 
Table 5 Parameters of hot-spot regression points for quadratic extrapolation

\begin{tabular}{lllll}
\hline $\begin{array}{l}\text { Quadratic extrapolation (X-type) } \\
\begin{array}{l}\text { Position of regression points } \\
\text { (mm from singularity point) }\end{array}\end{array}$ & $\begin{array}{l}\text { Stress from numeric } \\
\text { model (MPa) }\end{array}$ & $\begin{array}{l}\text { Position of regression points } \\
\text { (mm from singularity point) }\end{array}$ & $\begin{array}{l}\text { Stress from } \\
\text { numeric model } \\
\text { (MPa) }\end{array}$ \\
\hline $0.4 \mathrm{xt}$ & 108.67 & & 4 & 143.32 \\
$0.9 \mathrm{xt}$ & 104.92 & 8 & 129.18 \\
$1.4 \mathrm{xt}$ & 105.42 & 12 & 122.80 \\
hot-spot & 114.73 & Hot-spot & 165.21 \\
\hline
\end{tabular}

$\sigma_{h s, l i n}=1.67 \cdot \sigma_{0.4 t}-0.67 \cdot \sigma_{1.0 t}$

$\sigma_{h s, \text { quad }}=2.52 \cdot \sigma_{0.4 t}-2.24 \cdot \sigma_{0.9 t}+0.72 \cdot \sigma_{1.4 t}$
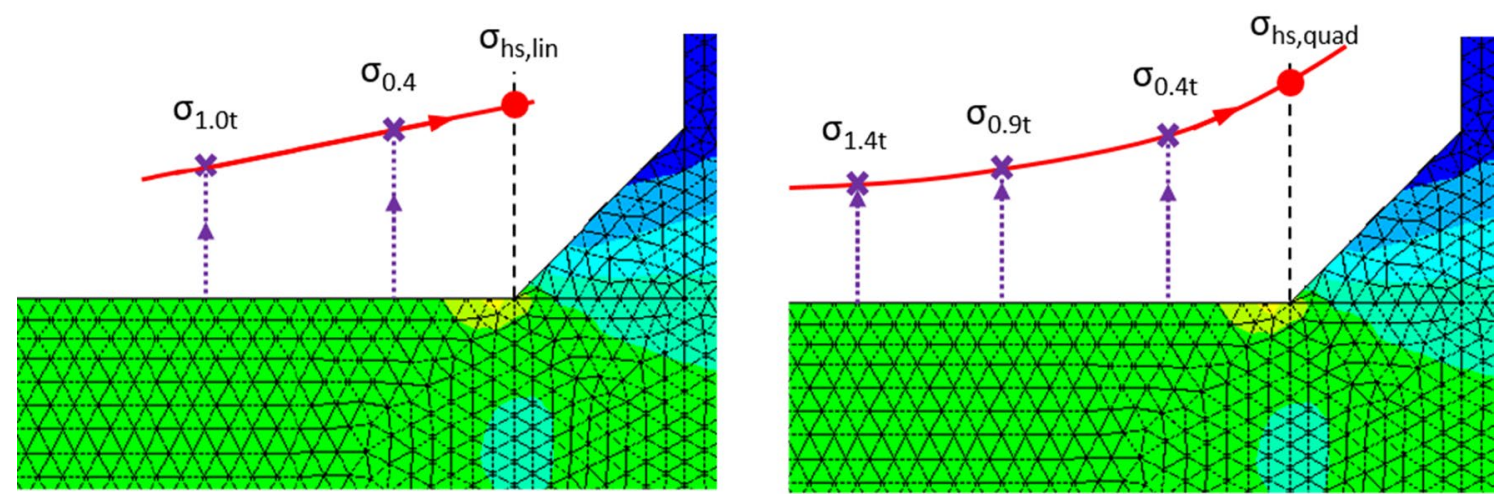

Fig. 11 Regression line of linear and quadratic hot-spot method for X-type specimens
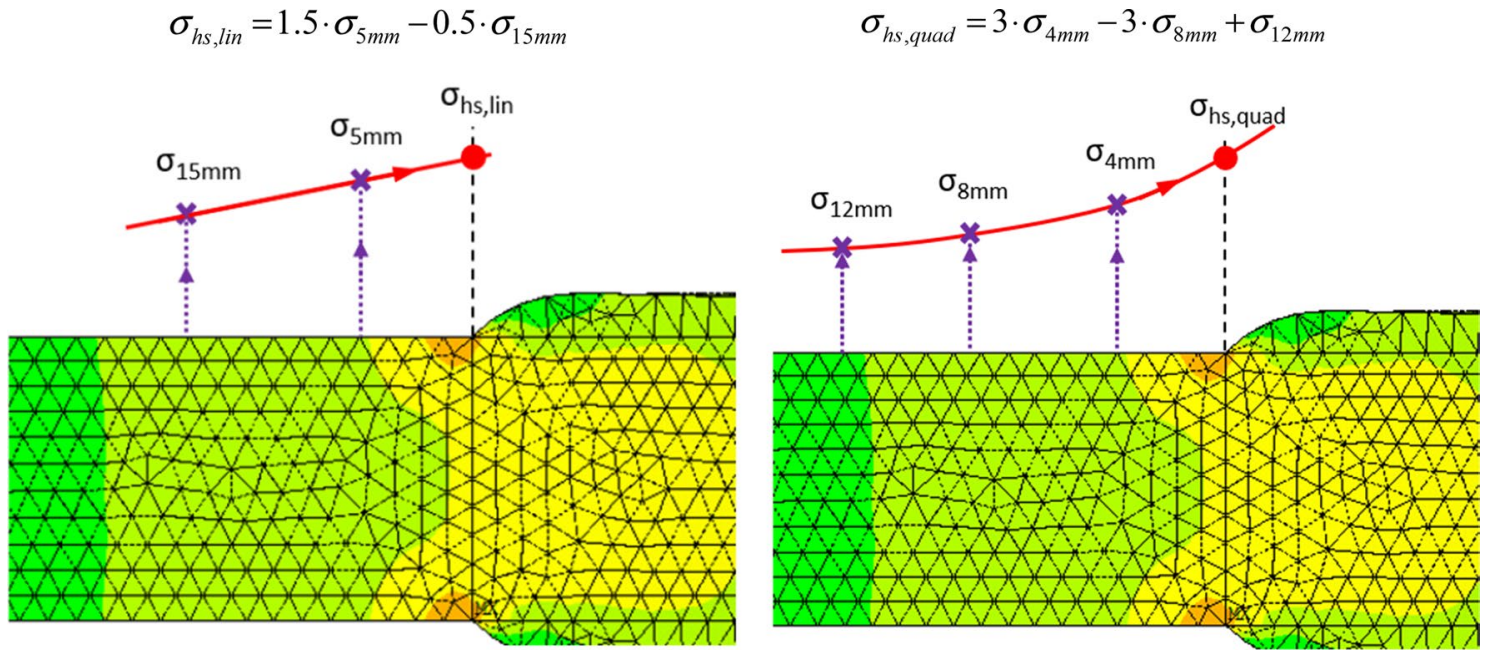

Fig. 12 Regression line of linear and quadratic hot-spot method for II-type specimens

by uniformly distributed axial load. The sum of the force depends on the investigated specimen according to Tables 1 and 2. The axial normal stresses are determined in the regression points, and these values are used to determine the hot-spot stresses (Figs. 11, 12). One example is shown in Tables 4 and 5.

\subsection{Numerical Models for Effective Notch Stress Approach}

3D models are developed to investigate the effective notch stress approach. The size and the type of applied elements were chosen according to Table 6 . 
Table 6 Recommended element types and element sizes for ENS method

\begin{tabular}{llll}
\hline $\begin{array}{l}\text { Element type } \\
\text { (displacement } \\
\text { function) }\end{array}$ & Relative size & Size for $r_{\text {ref }}=1 \mathrm{~mm}$ & Estimated error \\
\hline $\begin{array}{l}\text { Quadratic } \\
\text { (e.g. with }\end{array}$ & $\leq r_{\text {ref }} / 4$ & $\leq 0.25 \mathrm{~mm}$ & $\sim 2 \%$ \\
$\begin{array}{l}\text { mid-side } \\
\text { nodes) }\end{array}$ & & \\
\begin{tabular}{l} 
Linear \\
\hline
\end{tabular} & $\leq r_{\text {ref }} / 6$ & $\leq 0.15 \mathrm{~mm}$ & $\sim 10 \%$ \\
\hline
\end{tabular}

The settings of the numerical model act upon the recommendations of the IIW (Hobbacher 2014). The model is based on a twenty-node structural solid element. The

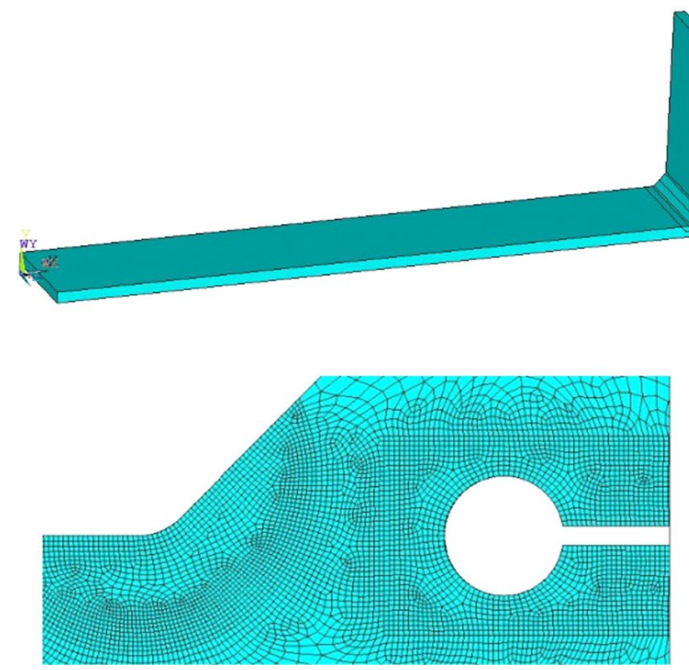

Fig. 13 Numeric model of X-type and II-type specimen

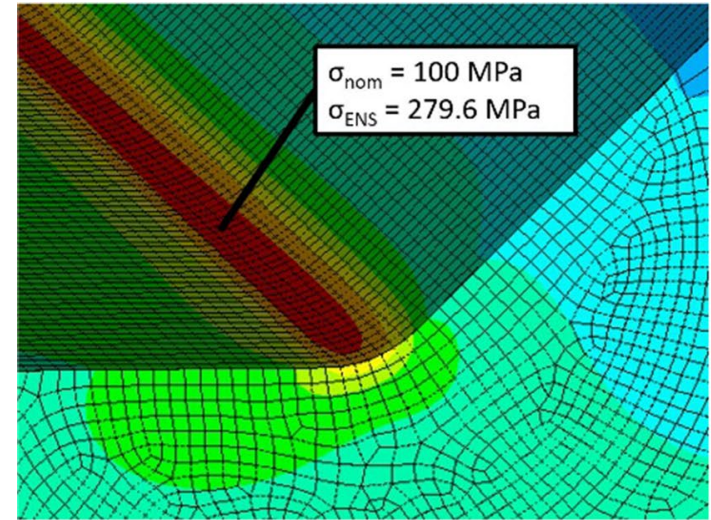

(a) benefits of these element types are that they have quadratic base functions and they are suitable to model irregular meshes. The effective notch root and weld toe radius are modelled by using $r_{\text {ref }}=1 \mathrm{~mm}$. The element size is $0.15 \mathrm{~mm}$ close to the fatigue critical point, and $0.5 \mathrm{~mm}$ far from this region. The symmetry of the details is used to reduce the number of the applied elements. The numerical model geometry, the applied finite element mesh and specific stress distributions are presented in Figs. 13 and 14 for both X-type and II-type specimens.

The supports correspond to the symmetry conditions. The model is loaded by uniformly distributed axial load. The 1st principal stress is determined at the fatigue critical point and this value is used to evaluate the recommended S-N curves.
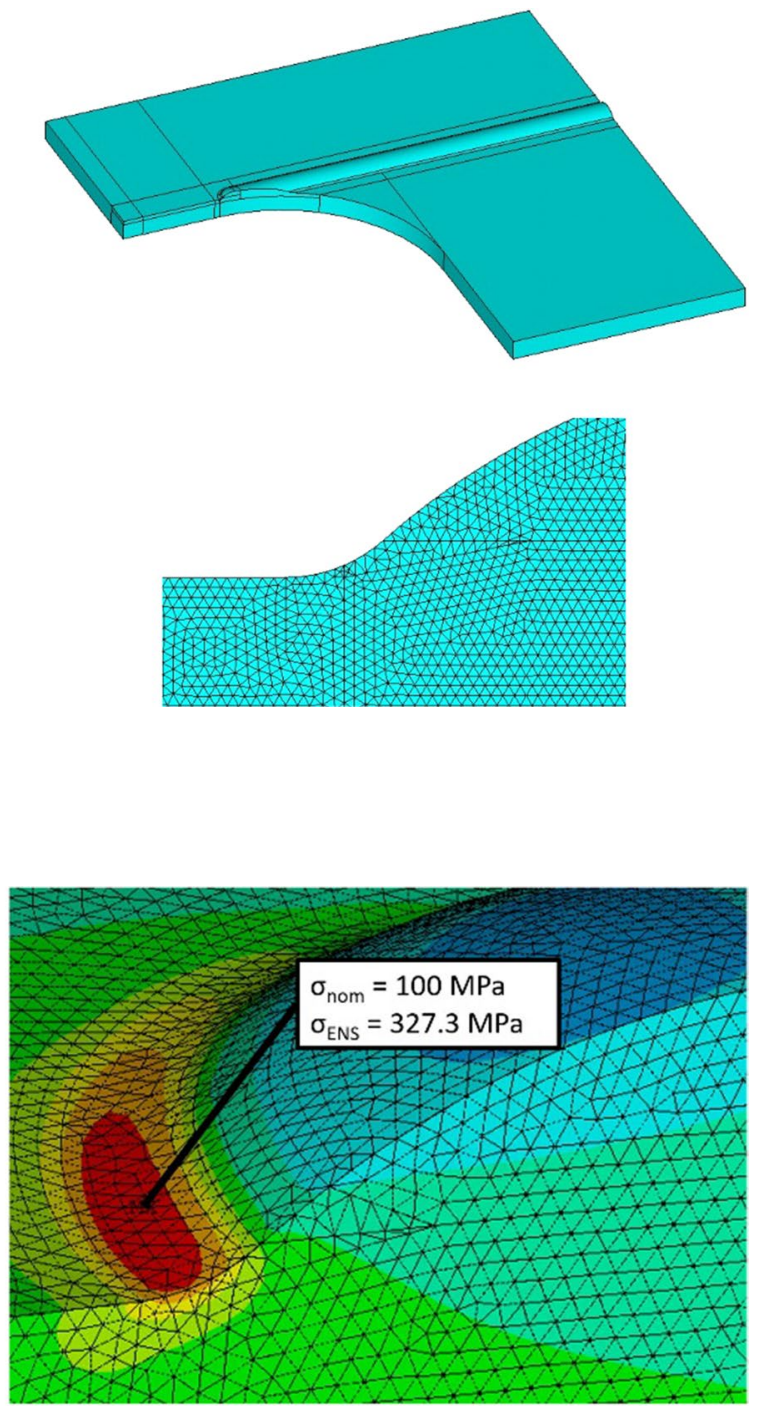

(b)

Fig. 14 Calculated ENS from FEM of X-type $\mathbf{a}$ and II-type $\mathbf{b}$ specimens 


\subsubsection{Comparison of the Numeric Models of Hot-Spot and Effective Notch Stress Approaches}

On the one hand, effective notch stress approach is more favourable than hot-spot method, because there is no restrictions in geometric shapes of the investigated structural details; it can be used for every type of possible geometries. Moreover, the effect of multiaxial loading can be studied with it also. On the other hand, building the numerical model of ENS method is not easy, because the complex geometrical details have to be modelled as well. Other disadvantage of ENS approach is the size of the numerical models. To demonstrate of this property the degrees of freedom (DOF) of previously presented four numerical models are given in Table 7. It can be observed that there is a remarkable difference between the sizes of hot-spot and ENS models. The sizes of numeric models of $\mathrm{X}$ - and II-type specimens are quite different because of the different length of the investigated weld toe parts. However, the ratios between DOFs of hot-spot and ENS models are approximately the same for both structural details.

Table 7 Sizes of numeric models for hot-spot and ENS approaches

\begin{tabular}{llll}
\hline $\begin{array}{l}\text { Type of speci- } \\
\text { men }\end{array}$ & $\begin{array}{l}\text { DOF numeric } \\
\text { model for hot- } \\
\text { spot approach }\end{array}$ & $\begin{array}{l}\text { DOF numeric } \\
\text { model for ENS } \\
\text { approach }\end{array}$ & $\begin{array}{l}\text { Ratio between } \\
\text { DOFs of hot- } \\
\text { spot and ENS } \\
\text { model }\end{array}$ \\
\hline X-type & 157,153 & 719,402 & 4.57 \\
II-type & 30,516 & 126,375 & 4.14 \\
\hline
\end{tabular}

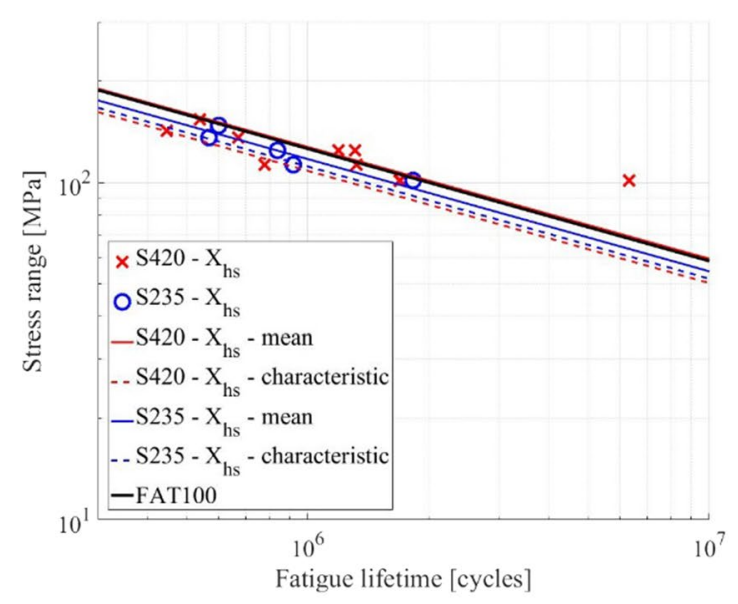

(a)

\subsection{Statistical Evaluation of the Numerical and Test Results}

To compare the different local stress approaches, the fatigue test results are processed by the results of the numerical model. According to the results of the fatigue tests, the mean and characteristic $\mathrm{S}-\mathrm{N}$ curves are determined and the fatigue strength, which belongs to the fatigue lifetime of 2 million cycles is compared to the standard fatigue detail class. The experimental S-N curves are determined using a modified least square method, where the slope of the regression is set equal to 3.0. The mean $\mathrm{S}-\mathrm{N}$ curves are the results of the modified least square method. Thus this curve has 50\% possibility that the fatigue experimental results are above it. The characteristic $\mathrm{S}-\mathrm{N}$ curves were defined to satisfy the condition that this curve has $90 \%$ possibility that the fatigue experimental results are above it.

\subsection{Comparison of the Hot-Spot S-N Curves and the Experimental Results}

\subsubsection{Results of the X-Type Specimens}

The evaluation based on the hot-spot stresses computed by the numerical model and the fatigue lifetimes based on the test results are presented in Fig. 15 by using linear or quadratic extrapolation function, respectively. The results prove that the proposed design fatigue detail class FAT100 (Hobbacher 2014) shows good agreement with the test results. In the case of linear regression the difference between these two curves is $-11.2 \mathrm{MPa}$ by $2 \times 10^{6}$ fatigue lifetime (Fig. 15a). Upon using quadratic extrapolation, the $\mathrm{S}-\mathrm{N}$ curve is closer to the standard curve, the difference is $-8.11 \mathrm{MPa}$ (Fig. 15b).

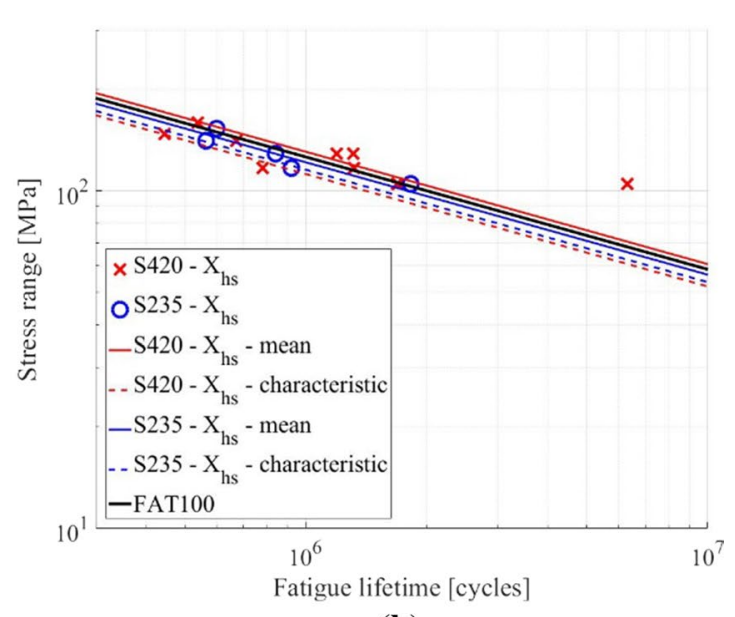

(b)

Fig. 15 Results of a linear and $\mathbf{b}$ quadratic hot-spot method for X-type specimens 


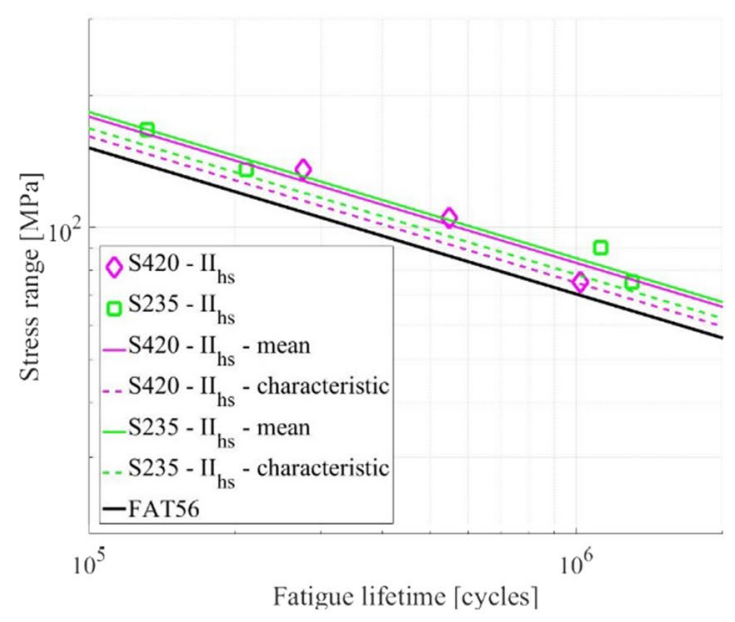

(a)

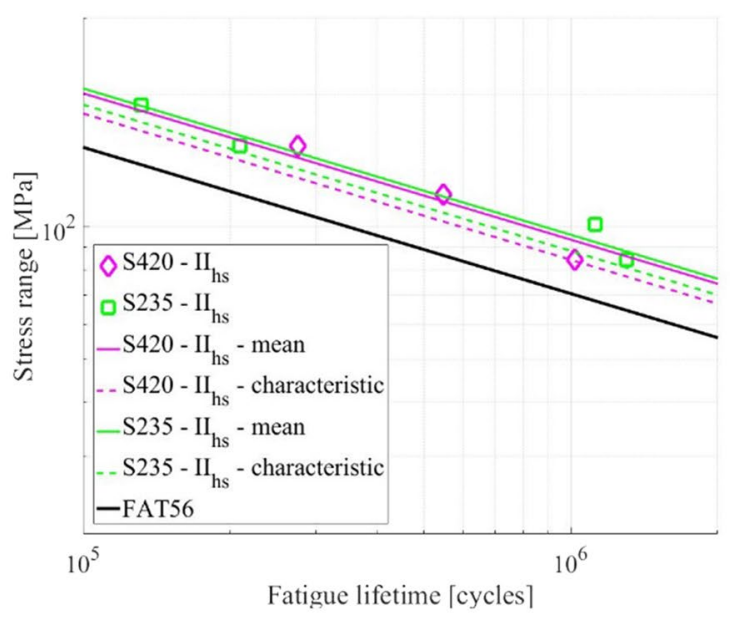

(b)

Fig. 16 Results of a linear and $\mathbf{b}$ quadratic hot-spot method for II-type specimens

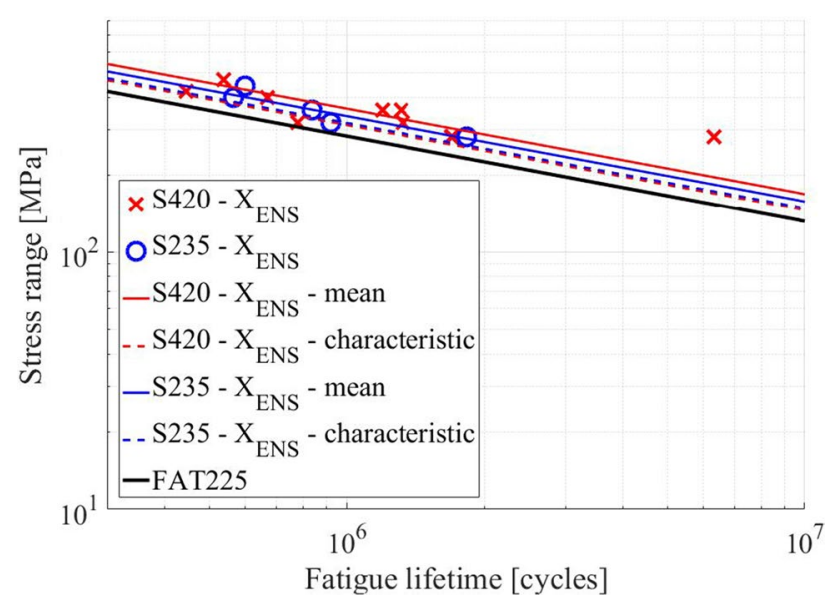

Fig. 17 Results of ENS method for X-type specimens

\subsubsection{Results of the II-Type Specimens}

There is no recommended hot-spot type $\mathrm{S}-\mathrm{N}$ curve for this structural detail (Hobbacher 2014). However, according to the characteristic S-N curve of the current experimental and numerical results, the FAT56 curve can be used for the fatigue design of this detail. Applying this fatigue detail class, the results of the linear extrapolation is $+2.88 \mathrm{MPa}$ over of the FAT56 curve (Fig. 16a), at the $2 \times 10^{6}$ fatigue lifetime. The results based on the quadratic extrapolation are more above of FAT56 (Fig. 16b), the difference is + 10.18 MPa.

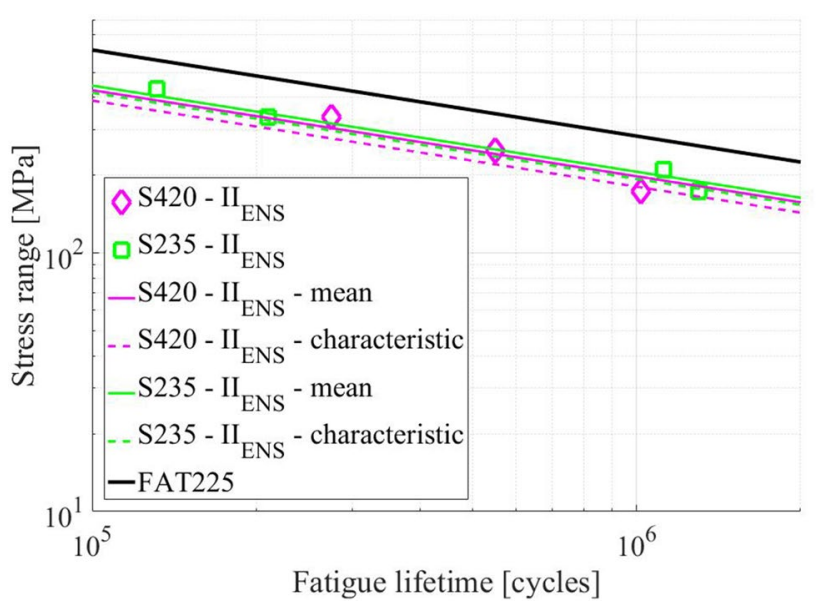

Fig. 18 Results of ENS method for II-type specimens

\subsection{Comparison of the Effective Notch Stress S-N Curves and the Experimental Results}

\subsubsection{Results of the X-Type Specimens}

The results prove that the ENS method is applicable to cruciform structural details with high accuracy according to the current experimental and numerical research program. The characteristic S-N curve, determined from data points of the tests results, is located above the FAT225 S-N curve, the obtained difference is $+27.28 \mathrm{MPa}$ (Fig. 17).

\subsubsection{Results of the II-type specimens}

On the other side the results prove that the ENS method is not adequate for II-type structural details. Upon investigating 
the test results of these specimens, it can be observed, that the characteristic $\mathrm{S}-\mathrm{N}$ curve is below the recommended FAT225 curve. The difference is $-80.90 \mathrm{MPa}$ by $2 \times 10^{6}$ fatigue lifetime (Fig. 18). The current results show that the ENS method can be applied carefully, and it is recommended only for previously tested and studied structural details, where the applicability of the method is verified. If a new structural geometry is required to be analysed, the applicability of this method should be verified by new fatigue tests, however the main aim of the method was to reduce the number of the necessary fatigue experiments.

\subsubsection{The Effect of the Model Parameters on the ENS Method}

According to the base assumption of the ENS method, the plotted test results of the two types of specimens would have to fit to the same $\mathrm{S}-\mathrm{N}$ curve, which is not the case based on the current results. The statistical analysis have shown that the $S-N$ curves of X-type and II-type specimens are different. Therefore, the ENS method cannot be applied to all structural details where the same numerical model settings are used. The plotted results of X-type joints are above the recommended FAT225 $S-N$ curve, however, the results of the II-type specimens are located under this curve. In the current Section it is studied which model parameters would fit to both structural details, making the FAT225 curve applicable to the II-type specimens as well. A numerical parametric study is executed to investigate the effect of the mesh size and the rounding radius on the $\mathrm{S}-\mathrm{N}$ curves. The element size $(l)$ is changed from the recommended $0.15 \mathrm{~mm}$ to $0.08 \mathrm{~mm}$; the reference radius $\left(r_{\text {ref }}\right)$ is decreased from the recommended $1 \mathrm{~mm}$ to $0.5 \mathrm{~mm}$ (Fig. 19) and the effective notch stress at fatigue critical point was investigated $\left(\sigma_{\mathrm{ENS}}\right)$. The investigated radius-element size pairs and the calculated effective notch stresses are summarized in Table 8.

Evaluating the results, it can be concluded that the element-size reduction has no significant effect on the local stress values. However, if the reference radius is decreased, the local stresses significantly increase. Therefore, if a smaller radius is applied to the II-type specimen, the computed stresses can be significantly increased and the obtained data points would be closer to the FAT225 S-N curve. The current numerical calculations showed that for the X-type joint the $r_{\text {ref }}=1 \mathrm{~mm}$ fits well to the FAT225 curve, however, for the II-type joints a radius of $r_{\text {ref }}=0,5 \mathrm{~mm}$ would be required to fulfil the safety requirement of the Eurocode, as shown in Figs. 20 and 21.

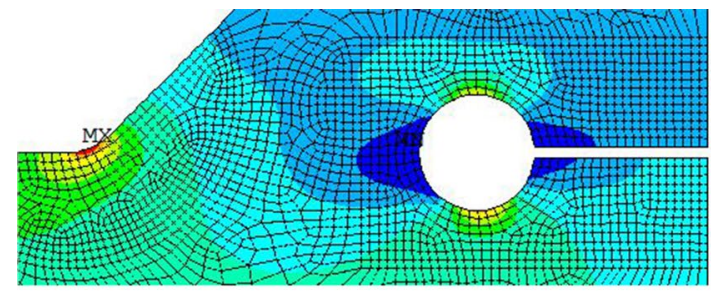

(a)

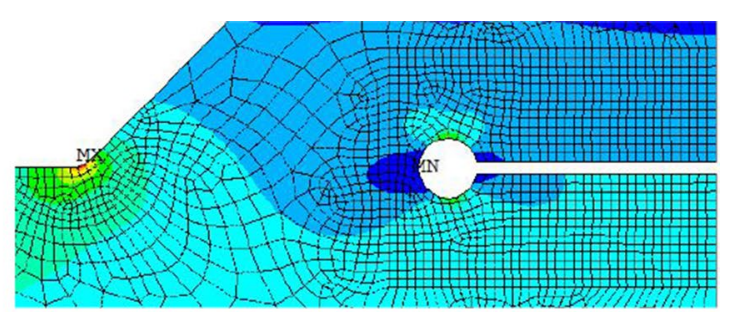

(b)

Fig. 19 Numerical model of X-type specimen with $\mathbf{a} \mathbf{r}_{\text {ref }}=1 \mathrm{~mm}$ and $\mathbf{b} r_{\text {ref }}=0.5 \mathrm{~mm}$

Table 8 Effective notch stresses and the parameters of the numerical investigation on $3 \mathrm{D}$ models

\begin{tabular}{|c|c|c|c|c|c|c|c|}
\hline \multirow[t]{3}{*}{$\sigma_{\mathrm{ENS}}(\mathrm{MPa})$} & & \multicolumn{3}{|c|}{ X-type specimens } & \multicolumn{3}{|c|}{ II-type specimens } \\
\hline & & \multicolumn{3}{|l|}{$\mathrm{L}(\mathrm{mm})$} & \multicolumn{3}{|l|}{$\mathrm{L}(\mathrm{mm})$} \\
\hline & & 0.15 & 0.10 & 0.08 & 0.15 & 0.10 & 0.08 \\
\hline \multirow[t]{8}{*}{$r_{r e f}(\mathrm{~mm})$} & 1.2 & 283.183 & 283.204 & 283.483 & 308.106 & 306.708 & 306.862 \\
\hline & 1.1 & 276.540 & 275.732 & 275.662 & 318.154 & 315.588 & 315.099 \\
\hline & 1.0 & 285.027 & 283.172 & 283.252 & 327.305 & 324.411 & 324.562 \\
\hline & 0.9 & 296.590 & 293.423 & 293.645 & 337.733 & 334.801 & 334.210 \\
\hline & 0.8 & 309.228 & 306.679 & 305.478 & 350.932 & 347.311 & 347.179 \\
\hline & 0.7 & 321.609 & 320.343 & 319.520 & 360.507 & 362.836 & 361.703 \\
\hline & 0.6 & 340.311 & 339.473 & 336.809 & 385.683 & 382.048 & 378.626 \\
\hline & 0.5 & 365.655 & 360.395 & 360.673 & 408.283 & 404.882 & 403.019 \\
\hline
\end{tabular}




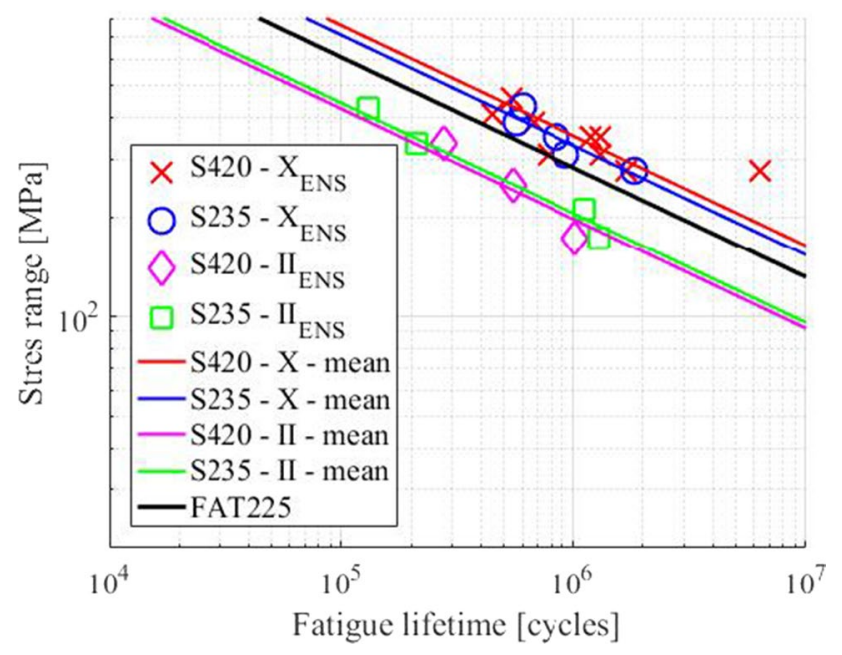

Fig. 20 S-N curves based on ENS models with $r_{\text {ref }}=1 \mathrm{~mm}$ for X-type, and II-type joints

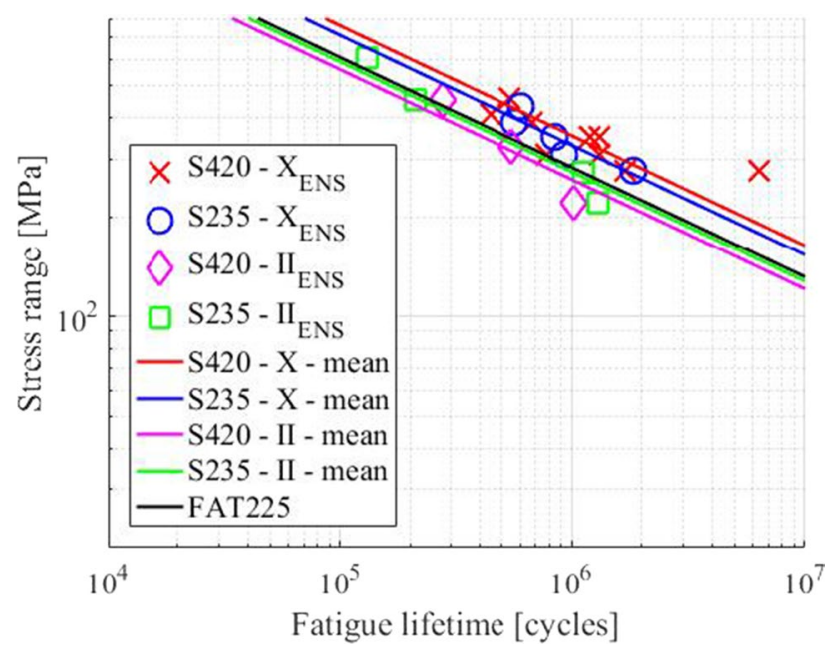

Fig. 21 S-N curves based on ENS models with $r_{\text {ref }}=1 \mathrm{~mm}$ for $\mathrm{X}$-type, and $\mathrm{r}_{\text {ref }}=0,5 \mathrm{~mm}$ for II-type joint

\section{Conclusions}

An experimental and numerical research program is executed at the BME Department of Structural Engineering in Hungary, by investigating the fatigue lifetime of X-type and II-type joints in order to evaluate the applicability of the hot-spot and effective notch stress based fatigue assessment methods. The accuracy of the hot-spot stress method and the ENS method is studied and evaluated based on fatigue test results. According to the statistical analysis of the test results, the following conclusions are made:

- The applicability of the IIW recommendations on the hot-spot and ENS method for fatigue design of cruci- form joints is proven by the current test results and by the executed statistical analysis.

- The IIW recommendations are extended for the fatigue assessment of a gusset plate joint, for which the current rules are still not verified. The results of the numerical parametric study showed that the ENS method could be also applied to a gusset plate joint at the reference radius of $r_{\text {ref }}=0,5 \mathrm{~mm}$.

Based on the results of the research program, it can be stated that the local stress methods are widely favourable and they can be economical for fatigue design. However, the experimental program also showed that more investigations and validation processes are required to use these methods widely for design purposes. Further ENS analysis of previously non-investigated structural details are required. Fatigue test results of different structural details should be investigated using ENS method, which was not studied by this approach. Applying statistical techniques, a new, applicable reference radius could be determined. Thus the original idea of ENS method could be reached: one universal fatigue class validated for more structural details.

Acknowledgements Open access funding provided by Budapest University of Technology and Economics (BME). The presented research results are part of the "BridgeBeam" R\&D Project No. GINOP-2.1.115-2015-00659. The executed research program was also supported by the ÚNKP-18-4 New National Excellence Program of the Ministry of Human Capacities; and by the János Bolyai Research Scholarship of the Hungarian Academy of Sciences; the financial supports are gratefully acknowledged.

Open Access This article is licensed under a Creative Commons Attribution 4.0 International License, which permits use, sharing, adaptation, distribution and reproduction in any medium or format, as long as you give appropriate credit to the original author(s) and the source, provide a link to the Creative Commons licence, and indicate if changes were made. The images or other third party material in this article are included in the article's Creative Commons licence, unless indicated otherwise in a credit line to the material. If material is not included in the article's Creative Commons licence and your intended use is not permitted by statutory regulation or exceeds the permitted use, you will need to obtain permission directly from the copyright holder. To view a copy of this licence, visit http://creativecommons.org/licenses/by/4.0/.

\section{References}

Al Zamzami, I., \& Susmel, L. (2018). On the use of hot-spot stresses, effective notch stresses and the Point Method to estimate lifetime of inclined welds subjected to uniaxial fatigue loading. International Journal of Fatigue, 117(July), 432-449.

Al-Emrani, M., \& Aygül, M. (2014). Fatigue design of steel and composite structures. Göteborg: Chalmers Reproservice.

Baumgartner, J. (2017). Review and considerations on the fatigue assessment of welded joints using reference radii. International Journal of Fatigue, 101, 459-468. 
Bertini, L., Frendo, F., \& Marulo, G. (2018). Fatigue life assessment of welded joints by two local stress approaches: The notch stress approach and the peak stress method. International Journal of Fatigue, 110(January), 246-253.

Budano, S., Kuppers, M., Kaufmann, H., Meisozo, A.M., \& Davis, C. (2007). Application of high strength steel plates to welded deck components for ships and bridges subjected to medium/high service loads. In EUR22571EN.

de Back, J. (1987). The design aspects and fatigue behavior of tubular joints. In Proceedings of the 3rd international ECSC offshore conference steel marine structures (Vol. 3, pp. 205-223).

EN 1993-1-9. (2005). Eurocode 3: Design of steelstructuresPart 1-9: Fatigue (p. 2005). Brussels: European Comittee for Standardization.

Fricke, W., Gao, L., \& Paetzold, H. (2017). Fatigue assessment of local stresses at fillet welds around plate corners. International Journal of Fatigue, 101, 169-176.

Galtier, A., \& Statnikov, E. S. (2004). The influence of ultrasonic impact treatment on fatigue behaviour of welded joints in highstrength steel. Welding in the World, 48, 61-66.

Haagensen, P. J. (1997). IIW's round robin and design recommendations for improvement methods. In Proceedings of the IIW 50th annual assembly conference.

Hobbacher, A. (2004). Recommendations for fatigue design (Vol. 39(1)). Paris: Springer.

Hobbacher, A. F. (2009). The new IIW recommendations for fatigue assessment of welded joints and components-A comprehensive code recently updated. International Journal of Fatigue, 31(1), $50-58$.

Huther, I., Minard, V., Royer, Y., \& Lieurade, H. P. (2004). Burr grinding effect on the fatigue strength as regard to initial weld quality. Stuttgart: Diplomarbeit.

Kudryavtsev, Y., et al. (2007). Rehabilitation and repair of welded elements and structures by ultrasonic peening. Welding in the World, $51,47-53$

Kuhlmann, U., Dürr, A., Bergmann, J., \& Thumser, R. (2006). Effizienter Stahlbau aus höherfesten Stählen unter Ermündungsbeanspruchung.

Lagerquist, O., Clarin, M., Gozzi, J., Völling, B., Pak, D., \& Stötzl, J. (2007). Lifthigh-Efficient lifting equipment with extra highstrength steel. In EUR22569EN.

Lee, Y.-L., Pan, J., Hathaway, R., \& Barkey, M. (2005). Fatigue testing and analysis. Burlington: Elsevier Butterworth-Heinemann.

Lener, G., Lang, R., Ladinek, M., \& Timmers, R. (2018). A numerical method for determining the fatigue strength of welded joints with a significant improvement in accuracy. Procedia Engineering, 213, 359-373.

Meneghetti, G., \& Lazzarin, P. (2007). Significance of the elastic peak stress evaluated by FE analyses at the point of singularity of sharp V-notched components. Fatigue and Fracture of Engineering Materials and Structures, 30(2), 95-106.

Muck, A. (2005). Ertüchtigung von ermüdungsbeanspruchten Schweißverbindungen durch Anwendung von ultrasonic impact treatment (UIT).

Niemi, E. (2002). Structural stress approach to fatigue analysis of welded components. In IIW Doc. (vol. XIII-1819-)

Niemi, E., Fricke, W., \& Maddox, S. J. (2006). Fatigue analysis of welded components: Designer's guide to the structural hot-spot stress approach. Boca Raton: Woodhead Publishing.

Niemi, B. E., \& Marquis, G. (2002). Introduction to the structural stress approach to fatigue analysis of plate structures (pp. 73-90).
Ohta, A., Maeda, Y., \& Suzuki, N. (2002). Residual stress effect on fatigue strength of nonload-carrying cruciform welded joints of SM570Q steel for welded structures. Welding in the World, 46(11-12), 20-25.

Ohta, A., Suzuki, N., \& Maeda, Y. (2003). Shift of S-N curves with stress ratio. Welding in the World, 47, 19-24.

Olivier, R., Köttgen, V. B., \& Seeger, T. (1989). Schweissverbindung I, FKM Forschungshefte 143. Frankfurt.

Olivier, R., Köttgen, V. B., \& Seeger, T. (1994). Schweissverbindung II, FKM Forschungshefte 143. Frankfurt.

Pedersen, M. M., Mouritsen, O. O., Hansen, M. R., Andersen, J. G., \& Wenderby, J. (2010a). Re-analysis of fatigue data for welded joints using the notch stress approach. International Journal of Fatigue, 32(10), 1620-1626.

Pedersen, M. M., Mouritsen, O., Hansen, M. R., Andersen, J. G., \& Wenderby, J. (2010b). Comparison of post-weld treatment of high-strength steel welded joints in medium cycle fatigue. Welding in the World, 54(7-8), 208-217.

Radaj, D. (1996). Review of fatigue strength assessment of nonwelded and welded structures based on local parameters. International Journal of Fatigue, 18(3), 153-170.

Radaj, D., Lazzarin, P., \& Berto, F. (2013). Generalised Neuber concept of fictitious notch rounding. International Journal of Fatigue, $51,105-115$.

Radaj, D., Sonsino, C. M., \& Fricke, W. (2006). Fatigue assessment of welded joints by local approaches (2nd ed.). Cambridge: Woodhead Publishing.

Rother, K., \& Fricke, W. (2016). Effective notch stress approach for welds having low stress concentration. International Journal of Pressure Vessels and Piping, 147, 12-20.

Saad-Eldeen, S., Tran Nguyen, K., Garbatov, Y., \& Guedes Soares, C. (2010). Fatigue stress assessment accounting for contact effect. In 10th international conference on marine sciense and technologies (pp. 23-33).

Sonsino, C. M. (2009). A consideration of allowable equivalent stresses for fatigue design of welded joints according to the notch stress concept with the reference radii rref $=1.00$ and $0.05 \mathrm{~mm}$. Welding in the World, 53(3-4), R64-R75.

Sonsino, C. M., Bruder, T., \& Baumgartner, J. (2010). S-N lines for welded thin joints-Suggested slopes and fat values for applying the notch stress concept with various reference RADII. Welding in the World, 54(11-12), 375-392.

Sonsino, C. M., Fricke, W., De Bruyne, F., Hoppe, A., Ahmadi, A., \& Zhang, G. (2012). Notch stress concepts for the fatigue assessment of welded joints-Background and applications. International Journal of Fatigue, 34(1), 2-16.

Statnikov, E. S., Muktepavel, V. O., Blomqvist, A., \& Company, T. (2002). Comparison of ultrasonic impact treatment (UIT) and other fatigue life. Welding in the World, 46, 20-32.

Taras, A., \& Unterweger, H. (2013). Proposal for a stress modification factor for the fatigue design of flange thickness transitions in welded girders. Engineering Structures, 56, 1758-1774.

Zhang, Y., Xiao, Z., \& Luo, J. (2018). Fatigue crack growth investigation on offshore pipelines with three-dimensional interacting cracks. Geoscience Frontiers, 9(6), 1689-1697.

Publisher's Note Springer Nature remains neutral with regard to jurisdictional claims in published maps and institutional affiliations. 